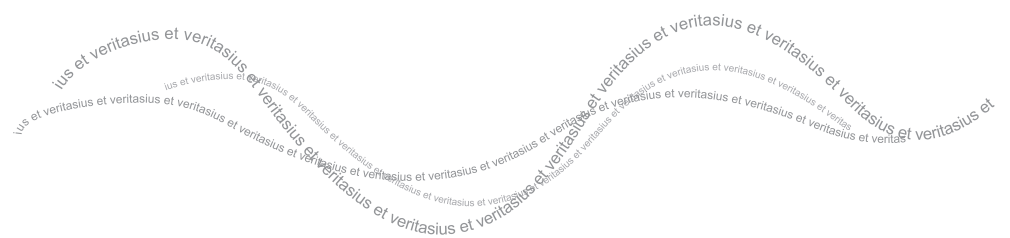

\title{
Aspectos problemáticos en los inmuebles sujetos a dominio fiduciario: tratamiento del impuesto de alcabala y las medidas cautelares( ()$^{(*)}$
}

\section{Problematic areas in the real property subjects to a fiduciary domain: sales tax treatment and the provisionary measures}

\author{
Julio Pozo Sánchez ${ }^{(* *)}$ \\ Universidad Nacional Mayor de San Marcos
}

Carolina Ormeño Flores ${ }^{(* * * *)}$

Universidad Nacional Mayor de San Marcos

\begin{abstract}
Resumen: De acuerdo a la legislación peruana, a través del contrato de fideicomiso, el fideicomitente transfiere en dominio fiduciario a favor del fiduciario diversos bienes, derechos y obligaciones, los mismos que deben ser afectados a la consecución de un determinado fin. De tal manera se constituye un patrimonio autónomo que no responde por las obligaciones del fideicomitente ni del fiduciario. Pese a la claridad de dichas disposiciones, los autores evidencian que en la realidad se presentan situaciones problemáticas de concepto que tienen consecuencias prácticas con el tratamiento de los inmuebles sujetos a dominio fiduciario.
\end{abstract}

Palabras clave: Fideicomiso - Dominio Fiduciario - Alcabala - Tercería Excluyente de Propiedad - Embargos sobre Inmuebles - Fideicomitente Fiduciario.

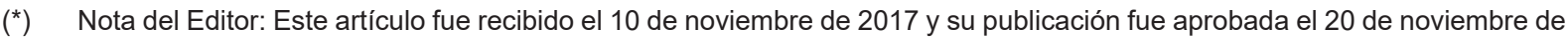
2017.

${ }^{* *}$ Los autores desean expresar su agradecimiento en la elaboración del presente artículo a Piero Cortina Gonzales, destacado alumno del cuarto año de Derecho en la Universidad Nacional Mayor de San Marcos y miembro principal del Grupo de Estudios de Derecho Inmobiliario-GEDI.

$\left({ }^{* * *}\right.$ ) Abogado por la Universidad Nacional Mayor de San Marcos, con Título de Post Grado de Especialización en Estrategias de Negociación por la Universidad de Castilla - La Mancha (España). Se ha desempeñado como profesor de Derechos Reales en la Universidad Nacional Mayor de San Marcos. Asesor Principal \& Fundador del Grupo de Estudios de Derecho Inmobiliario-GEDI. Consultor en temas de Juntas de Propietarios y litigios inmobiliarios. Correo electrónico: pyvabogados@ gmail.com

$\left.{ }^{(* \star *}\right)$ Egresada de la carrera de Derecho por la Universidad Nacional Mayor de San Marcos. Sub Coordinadora del Grupo de Estudios de Derecho Inmobiliario-GEDI. Correo electrónico: carolinadelpilar.o.f@gmail.com 


\author{
Aspectos problemáticos en los inmuebles sujetos a dominio fiduciario: tratamiento \\ del impuesto de alcabala y las medidas cautelares \\ Problematic areas in the real property subjects to a fiduciary domain: sales tax \\ treatment and the provisionary measures
}

\begin{abstract}
According to Peruvian legislation, through an escrow agreement a trustor transfers under a fiduciary domain in favor of an escrow agent various goods, rights and obligations, which must achieve certain purpose. These will constitute an autonomous patrimony that does not respond any obligation of the trustor and the agent escrow. Despite the clarity of this statement, the authors reveal that indeed there might be different interpretations about this agreement that have practical consequences with the treatment of real properties subject to fiduciary dominion.
\end{abstract}

Keywords: Escrow Agreement - Fiduciary Domain - Excise Third Party Property Exclusion - Foreclosures on Real Estate - Trustor - Trustee

Sumario: 1. Introducción_2. Aspectos generales del fideicomiso_3. Naturaleza del dominio fiduciario y su trascendencia en caso de inmuebles_3.1. Impuesto de alcabala_3.2. Dominio fiduciario y transferencia de propiedad_3.3. Fideicomiso e impuesto de alcabala_4. La defensa del patrimonio autónomo ante las medidas cautelares_4.1. Titularidad del patrimonio autónomo_4.2. Intervención excluyente de propiedad en materia tributaria_5. Conclusiones

\section{Introducción}

El fideicomiso en el Perú es un contrato típico que se encuentra regulado principalmente en dos instrumentos normativos: la Ley 26702, Ley del Sistema Financiero y de Seguros y Ley Orgánica de la Superintendencia de Bancos y Seguros ${ }^{(1)}(E n$ adelante, "Ley de Bancos") y el Decreto Supremo No. 0932002-EF, Texto Único Ordenado de la Ley del Mercado de Valores $^{(2)}$, (En adelante, "Ley de Mercado de Valores"). Ambos dispositivos coinciden en definirlo como una operación a través de la cual el fideicomitente transfiere el dominio fiduciario de cierto patrimonio, constituyéndolo en autónomo, es decir, protegido frente a afectaciones por parte de los acreedores del fideicomitente y del fiduciario, e incluso de los fideicomisarios.

Sobre el particular, en la primera parte del presente trabajo analizaremos si la transmisión de un inmueble en dominio fiduciario, en el marco de la celebración de un contrato de fideicomiso, implica la transferencia de propiedad de dichos inmuebles. De la respuesta afirmativa o negativa se desplegarán diversos efectos prácticos, entre los cuales encontramos el referido al pago del impuesto de alcabala, por ejemplo.

En la segunda parte analizaremos las implicancias de considerar al patrimonio que se forma a través de un fideicomiso como autónomo y el tratamiento que se le da a las medidas cautelares interpuestas por la Superintendencia Nacional de Aduanas y de Administración Tributaria (En adelante, "SUNAT") contra los inmuebles sujetos a dominio fiduciario por obligaciones del fideicomitente.

\section{Aspectos generales del fideicomiso}

La doctrina define al fideicomiso como "el negocio jurídico en virtud del cual se transfieren uno o más bienes a una persona con el encargo de que los administre o los enajene y que, con el producto de su actividad cumpla una finalidad establecida por el constituyente, en su favor o en beneficio de un tercero" (Rodríguez 2005). Con otros matices, se le conoce como "un contrato por el cual una persona (el fiduciario) se compromete frente a otra (el fideicomitente) a realizar un encargo o acto de administración sobre los bienes que dicha persona le transmite en propiedad; comprometiéndose a entregar los frutos o beneficios que se obtengan de la administración de dichos bienes a la persona que haya sido designada como beneficiario (o fideicomisario del fideicomiso.

(1) Así como el Reglamento del Fideicomiso y de las Empresas de Servicios Fiduciarios, aprobado por Resolución SBS No. 1010-99.

(2)| Así como el Reglamento de los Procesos de Titulización de activos, aprobado por Resolución CONASEV 001-97-EF. 


\section{Julio Pozo Sánchez y Carolina Ormeño Flores}

De lo anterior, podemos advertir que en una operación de fideicomiso se distinguen tres partes: (i) el fideicomitente, que viene a ser la persona titular de los bienes o derechos que se transmiten al fiduciario para el cumplimiento de una finalidad; (ii) el fiduciario, que como veremos más adelante, únicamente puede ser una persona autorizada por la Superintendencia de Banca, Seguros y AFP(3) para desempeñarse como tal; cuya participación en el contrato de fideicomiso se encuentra circunscrita a administrar los bienes o derechos que transmite el fideicomitente para la consecución de la finalidad establecida; y (iii) el fideicomisario, que viene a ser la persona o personas que reciben el beneficio del fideicomiso, o la que recibe los remanentes una vez cumplida la finalidad perseguida a través del fideicomiso. Cabe indicar que el fideicomitente puede a su vez ser el beneficiario o fideicomisario del fideicomiso.

Ahora bien, el artículo 241 de la Ley de Bancos señala que el fideicomiso es una relación jurídica por la cual el fideicomitente transfiere bienes en fideicomiso a otra persona, denominada fiduciario, para la constitución de un patrimonio fideicometido, sujeto al dominio fiduciario de este último y afecto al cumplimiento de un fin específico en favor del fideicomitente o un tercero denominado fideicomisario. Nótese, entonces, que "en virtud del negocio fiduciario uno de los sujetos (fiduciante) transfiere al otro (fiduciario) determinado derecho, con la condición de que este último: (i) lo ejerza en cierta forma; y, (ii) lo retransfiera a la ocurrencia de un hecho (típicamente, el pago de una deuda o la desaparición de una restricción o peligro)" (Escobar 2006).

Es preciso indicar que la Ley de Bancos regula los distintos tipos de fideicomiso, excepto a los fideicomisos de titulización que se encuentran establecidos en la Ley de Mercado de Valores. En tal sentido, el artículo 301 de la Ley de Mercado de Valores, cuando hace referencia al fideicomiso de titulización señala que:

\begin{abstract}
"en el fideicomiso de titulización, una persona denominada fideicomitente, se obliga a efectuar la transferencia fiduciaria de un conjunto de activos en favor del fiduciario para la constitución de un patrimonio autónomo, denominado patrimonio fideicometido, sujeto al dominio fiduciario de éste último y que respalde los derechos incorporados en valores cuya suscripción o adquisición concede a su titular la calidad de fideicomisario"(4).
\end{abstract}

De lo expuesto hasta el momento, nos importa resaltar tres características del fideicomiso. La primera está referida a la finalidad de la constitución de un fideicomiso. En efecto, el fideicomitente transfiere al fiduciario los bienes fideicometidos para que este los administre, y despliegue una serie de facultades otorgadas en el contrato de fideicomiso y en las normas a fin de materializar el objetivo para el cual fue constituido. La finalidad del fideicomiso puede ser diversa, siempre que sea lícita, es por ello que con acierto se menciona que

"esta característica del fideicomiso ofrece un elemento que puede determinar el interés de los agentes económicos y las personas en general para efectos de decidir su utilización, ya que el fideicomiso puede establecerse con la finalidad de satisfacer cualquier necesidad que pudiesen tener los agentes económicos y las personas en general" (Corzo de la Colina 2012).

(3) O por la Superintendencia de Mercado de Valores, en el caso de los fideicomisos de titulización.

(4) Cabe indicar que al fideicomiso de titulización también se le conoce como securitización, que deriva del inglés security, o título valor financiero. En consecuencia, nótese que "la securitización es una forma de acelerar el ciclo del flujo de distintos negocios, utilizando como base diversos activos agrupados y creando en ellos estructuras convenientemente aisladas para que aseguren un grado suficiente de garantías a las fuentes de financiamiento, que alcanzará mediante la colocación de títulos-valores o participaciones en el flujo de fondos productos por estos activos subyacentes". En Silvio Lisopraswki, "Securitización," en Fideicomiso. Dominio fiduciario. Securitización 2a ed., Silvio Lisopraswki Y Claudio Kiper (Buenos Aires: Depalma, 1996), 1-24. En concordancia con ello, la Ley de Mercado de Valores establece que la titulización es el proceso mediante el cual se constituye un patrimonio cuyo propósito exclusivo es respaldar el pago de los derechos conferidos a los titulares de valores emitidos con cargo a dicho patrimonio. 


\author{
Aspectos problemáticos en los inmuebles sujetos a dominio fiduciario: tratamiento \\ del impuesto de alcabala y las medidas cautelares \\ Problematic areas in the real property subjects to a fiduciary domain: sales tax \\ treatment and the provisionary measures
}

La segunda característica es una consecuencia de la finalidad establecida por el fideicomitente en el acto constitutivo del fideicomiso puesto que, para poder cumplir con tal finalidad, es necesario que el fideicomitente le otorgue al fiduciario diversas facultades, entre las que se encuentran las de administración, uso, disposición y reivindicación sobre los bienes que conforman el patrimonio fideicometido. A la gama de facultades que ejerce el fiduciario sobre los bienes sujetos a fideicomiso se le denomina dominio fiduciario, el mismo que debe ser ejercido dentro de los parámetros orientados a la consecución de la finalidad establecida por el fideicomitente en el contrato de fideicomiso.

Por su parte, la tercera característica está referida a la constitución de un patrimonio fideicometido o autónomo. Sobre este particular volveremos más adelante, no obstante, por lo pronto nos interesa mencionar que tanto la Ley de Bancos como la Ley del Mercado de Valores señalan expresamente que los bienes que son transmitidos en fideicomiso constituyen un patrimonio autónomo, el cual es distinto del patrimonio del fideicomitente, del fiduciario, del fideicomisario, y en su caso del destinatario de los bienes remanentes ${ }^{(5)}$.

\section{Naturaleza del dominio fiduciario y su trascendencia en caso de inmuebles}

Como hemos mencionado, mediante el contrato de fideicomiso, el fideicomitente transmite bienes y derechos al fiduciario para que este ejerza diversas facultades tendientes a la consecución de la finalidad para el cual se constituyó el fideicomiso. Al respecto, existen posturas que sostienen que el fiduciario adquiere un derecho real, es decir, consideran que dominio fiduciario se encuentra en la categoría de los derechos reales, y otros incluso niegan la posibilidad de existencia del dominio fiduciario y señalan que el fideicomitente transfiere la propiedad de los bienes cuando constituye el fideicomiso. Una tercera posición (ecléctica) sostiene que no hay razón para que el dominio fiduciario sea considerado como un derecho real, y con mayor énfasis niegan la posibilidad de que el fideicomitente transfiera la propiedad de los bienes. Nótese que la discusión no es banal y que tiene efectos prácticos, por ejemplo, en el caso de los inmuebles aportados a un fideicomiso puesto que, si consideramos que se ha efectuado una transferencia de propiedad, se habrá configurado el hecho imponible que nos obliga al pago del impuesto de alcabala.

\subsection{Impuesto de alcabala}

El impuesto de alcabala actualmente es regulado por la Ley de Tributación Municipal, cuyo texto único ordenado fue aprobado por el Decreto Supremo No. 156-2004-EF, dispositivo normativo que lo define como aquel tributo municipal que grava las transferencias de propiedad de bienes inmuebles urbanos o rústicos a título oneroso o gratuito, cualquiera sea su forma o modalidad. En consecuencia, los elementos que deben concurrir para el nacimiento de la obligación tributaria son: la transferencia de propiedad ${ }^{(6)}$, cualquiera sea su forma o modalidad, sin importar que sea a título gratuito u oneroso; y que se trate de una transferencia de inmuebles urbanos o rústicos.

Además, cabe mencionar que este impuesto es de realización inmediata, es decir nace automáticamente al momento en que opera la transferencia de propiedad de un inmueble. La base imponible, esto es, el monto a partir del cual se realiza el cálculo para su determinación es el valor de transferencia del inmueble o el valor del autovalúo, el que sea mayor. Sobre dicho monto se descuenta 10 UIT, que de acuerdo a la Ley de Tributación Municipal viene a ser un tramo que no está afecto al impuesto de alcabala. Si queda un remanente, se le aplicará la tasa del $3 \%$ y el resultado será el valor del tributo que se debe pagar. Considerando que las municipalidades distritales son acreedoras del impuesto de alcabala, no es difícil pensar que dichas entidades, a través del Servicio

(5) Segundo párrafo del artículo 241 de la Ley de Bancos y artículo 310 de la Ley de Mercado de Valores.

(6) No obstante, la Ley de Tributación Municipal admite la posibilidad de que algunas transferencias se encuentren inafectas. Ver artículos 27 y 28 de la referida Ley. 
Julio Pozo Sánchez y Carolina Ormeño Flores

de Administración Tributaria (En adelante, "SAT") de su jurisdicción, serán las más interesadas en recaudar este impuesto que, además, resulta oneroso cuando se trata de transferencia de inmuebles de gran envergadura. Para ello, deberán tener en cuenta que:

"el universo de las formas de transferencia de la propiedad son variadas, incluso pueden tener diversas combinaciones y nombres, pero si todas están orientadas a realizar la transferencia de las atribuciones inherentes a la propiedad al comprador o adquirente, ello determina que se afecta con el pago del impuesto de alcabala" (Alva 2014).

En la siguiente sección nos dedicaremos a analizar si la operación a través de la cual se transmite un inmueble a un fideicomiso debe tener el tratamiento de una transferencia de propiedad, pasible, por tanto, del pago del impuesto de alcabala.

\subsection{Dominio fiduciario y transferencia de propiedad}

Como comentamos, existen diversas posturas sobre la naturaleza del dominio fiduciario. Ello depende de la legislación que cada país adopte, por lo que nos circunscribiremos principalmente a lo mencionado por nuestra Ley de Bancos y la Ley de Mercado de Valores.

Repasando nuestra legislación, advertimos que el segundo párrafo del artículo 273 de la Ley de Bancos señala expresamente que el fiduciario no tiene propiedad sobre los bienes que le son transferidos mediante el fideicomiso y que solo es responsable de la administración del mismo. En efecto, la administración que el fiduciario debe ejercer sobre los bienes debe estar conducida a la consecución de la finalidad del fideicomiso establecido en el acto constitutivo, y por ello se le confieren, en palabras del artículo 252 de la misma ley, plenas potestades incluidas las de administración, uso, disposición, y reivindicación sobre los bienes que conforman el patrimonio fideicometido, dentro de las limitaciones (sobre todo de disposición) establecidas previamente por el fideicomitente.

Por su parte, el artículo 310 de la Ley de Mercado de Valores dispone que la sociedad titulizadora (fiduciaria) ejerce el dominio fiduciario sobre el patrimonio autónomo que se forma en el acto constitutivo, siendo que el artículo 313 de la norma en mención señala que: sobre el patrimonio fideicometido la sociedad titulizadora ejerce un dominio fiduciario, el mismo que le confiere plenas potestades, incluidas las de administración, uso, disposición y reivindicación sobre los activos que integran el patrimonio fideicometido, las mismas que son ejercidas con arreglo a la finalidad para la que fue constituido el fideicomiso y con observancia de las limitaciones que se hubieren establecido en el acto constitutivo.

En suma, de manera uniforme la Ley de Bancos y la de Mercado de Valores presentan al dominio fiduciario como una de las notas características del fideicomiso, distinguiéndola claramente con el derecho de propiedad, en la medida que el primero implica un derecho sobre los bienes que está limitado por el encargo que se confiere al fiduciario en virtud del contrato de fideicomiso y que sirve para el propósito que las partes hayan pactado.

"El fideicomitente transfiere al fiduciario los bienes fideicometidos en fideicomiso (en fiducia), los que quedan sometidos a su dominio fiduciario. En este sentido, debemos tener en consideración este elemento típico del fideicomiso, referido al hecho de que la transferencia de los bienes se efectúa como uno de los medios requeridos por la sociedad fiduciaria para poder cumplir con la finalidad establecida en el documento constitutivo del fideicomiso, y no como un fin mismo de la operación" (Corzo de la Colina 2012).

Entonces, si bien el dominio fiduciario implica una serie de facultades en cabeza del fiduciario, estas se encuentran limitadas por el encargo que se confiere en virtud del contrato de fideicomiso y que sirve para el propósito que las partes hayan pactado. Por tanto, nótese que el dominio fiduciario constituye una situación jurídica subjetiva distinta al derecho de propiedad y no le es equiparable en tanto 


\section{Aspectos problemáticos en los inmuebles sujetos a dominio fiduciario: tratamiento del impuesto de alcabala y las medidas cautelares Problematic areas in the real property subjects to a fiduciary domain: sales tax treatment and the provisionary measures}

que no concurren los elementos esenciales de éste, que de acuerdo a la doctrina clásica son el de ser un derecho absoluto, perpetuo y exclusivo.

Así pues, el derecho de propiedad es absoluto, es decir, le confiere al propietario todos los atributos sobre el bien, dentro del marco de la licitud. No obstante, tal como lo hemos venido comentando a lo largo del presente artículo, las facultades del fiduciario están circunscritas a la finalidad establecida por el fideicomitente. El artículo 923 del Código Civil establece que la propiedad es el poder jurídico que permite usar, disfrutar, disponer y reivindicar un bien. Sin embargo, el dominio fiduciario supone un haz de facultades sobre los activos que conforman el patrimonio autónomo que no es equiparable al que representa el derecho de propiedad; es decir, no contiene todas las facultades que conforman el contenido de dicho derecho real. Es notable que el fiduciario no ostenta la facultad de disfrutar, de hecho, tal facultad ha sido excluida del artículo 252 de la Ley de Bancos y 313 de la Ley de Mercado de Valores.

En el caso particular de los fideicomisos regulados por la Ley de Bancos, el artículo 258 de la Ley de Bancos prohíbe a los fiduciarios realizar operaciones, actos y contratos con los fondos o bienes de los fideicomisos en su propio beneficio y el artículo 265 determina que el fideicomiso será nulo cuando se designa como fideicomisario al fiduciario, excepto en los casos de fideicomisos de titulización. Y ello es así porque el legislador, atinadamente, ha decidido proteger al fideicomitente y a los fideicomisarios del actuar del fiduciario, en la medida que este último actúa en beneficio de los fideicomisarios y por interés del fideicomitente, no en el suyo propio, la recompensa por su participación se limita a la obtención de una retribución por la administración del patrimonio fideicometido.

En síntesis,

"el fideicomiso, por un lado, no confiere al fiduciario ninguna facultad de 'disfrute' respecto a los bienes fideicometidos, y por otro, determina que se otorguen ciertas facultades a favor del fiduciario, las cuales deberán ser ejercidas, necesariamente, conforme a la finalidad del fideicomiso y teniendo en consideración las limitaciones establecidas para ello" (Corzo de la Colina 2012).

Con mayor énfasis, se sostiene que

"es absolutamente imposible sostener que el fiduciario adquiere el derecho de propiedad sobre el activo transferido por el fideicomitente. En efecto, el fiduciario jamás adquiere algunas de las facultades que conforman el contenido del referido derecho, como por ejemplo la facultad de destruir el bien o la de modificarlo. Por tanto, sea cual sea la titularidad otorgada al fiduciario, aquella no puede ser equiparada a la propiedad que tenía el fideicomitente sobre los activos" (Escobar 2006) ${ }^{(7)}$

Por otro lado, el derecho de propiedad tiende a la perpetuidad, es decir que no se pierde por el simple uso, sino únicamente cuando el propietario decide disponer de él definitivamente o por prescripción adquisitiva de dominio. A comparación de ello, el fideicomiso está limitado temporalmente al cumplimiento de la finalidad o a 30 años $^{(8)}$ como máximo, según lo establece el artículo 251 de la Ley de Bancos y solo admite prórroga cuando lo autoriza la Superintendencia de Banca, Seguros y AFP.

De esta manera, podemos concluir que si bien el fiduciario tiene los bienes fideicometidos, éstos continúan siendo propiedad del

(7) Sobre el particular, quisiéramos manifestar que para nosotros resultaría posible que el fideicomitente le otorgue al fiduciario las facultades de destruir o modificar los bienes en el acto de constitución del fideicomiso, los mismos que estarían destinados al cumplimiento de la finalidad del fideicomiso. Por ejemplo, en el caso que el fideicomitente constituya un fideicomiso y aporte un edificio de 10 pisos para que sobre él se construya un moderno edificio multifamiliar de 20 pisos. El fiduciario debería encontrarse habilitado para destruir el edificio y sobre el terreno edificar uno nuevo; sin que la posibilidad de ejercicio de dicha facultad signifique que el fiduciario ha adquirido la propiedad del inmueble. 


\section{Julio Pozo Sánchez y}

\section{Carolina Ormeño Flores}

fideicomitente, con la salvedad de que por la constitución del fideicomiso dichos bienes quedan destinados a la realización de un fin lícito y determinado, que la propia ley protege al establecer que sólo podrán ejercerse respecto de ellos los derechos y acciones que se refieran a ese fin.

\subsection{Fideicomiso e impuesto de alcabala}

De lo expuesto, es fácil concluir que a través del fideicomiso no se transfiere el derecho de propiedad sobre los bienes, y por tanto, en el caso particular de los inmuebles, el fiduciario no estará obligado al pago del impuesto de alcabala en tanto que el hecho generador del impuesto no se ha configurado. En otras palabras,

"al estar el fideicomitente obligado a efectuar la transferecia fiduciaria de un conjunto de activos en favor del fiduciario para la constitución de un patrimonio autónomo; y al no ser esta una transferencia plena de derechos y de atributos de la propiedad, no estará gravado con el referido impuesto debido a que se pretende gravar son aquellas transferencias a patrimonios autónomos que supongan la transferencia definitiva de la propiedad" (Figueroa 2010).

Asimismo,

"Es pertinente mencionar que en la Ley de Tributación Municipal no se ha establecido una lista de las operaciones que pueden determinar cuando existe o no transferencia de propiedad, además que desde su vigencia no existe aprobación de algún reglamento del impuesto de alcabala, por lo que algunas entidades ligadas a la aplicación de la normatividad municipal han intentado regular este aspecto, lo cual consideramos que no es posible, ya que las municipalidades no tendrían competencia para poder reglamentar una norma de carácter general" (Alva 2014).

En efecto, ante la ausencia de un reglamento de alcabala, en el ámbito de Lima Metropolitana el SAT de Lima emitió el 19 de julio de 2008 la Directiva No. 001-006-00000012, según la cual están gravadas con el impuesto de alcabala las transferencias para la constitución de patrimonios autónomos.
Sobre el particular, se ha mencionado que "esta precisión interpretativa alcanza a la transferencia de propiedad para la constitución de fondos de inversión u otro tipo de patrimonios autónomos, pero no a la transferencia fiduciaria" (Villanueva 2013). Dicha precisión fue aclarada por el Oficio 001090-000 de 13 de agosto de 2008 emitido por el SAT- Lima, que a letra menciona:

"la referida Directiva señala en su numeral 4 inciso k) que se encuentran gravadas con el impuesto de alcabala, las transferencias que se realizan para la constitución de patrimonios autónomos. No obstante a ello, debemos precisar que dicha disposición no es de aplicación a los supuestos de transferencia del dominio fiduciario que se produce como consecuencia de la celebración de un contrato de fideicomiso"(9).

Y no solo eso, sino que también señala que:

"lo señalado anteriormente se sustenta en el hecho que, tal como se prevé en el artículo 21 de la Ley de Tributación Municipal, el impuesto de alcabala grava la transferencia de propiedad, situación que no se presenta en la constitución de dominios fiduciarios, puesto que conforme se indica en el artículo 273 de la Ley del Sistema Financiero y del Sistema de Seguros y Orgánica de la Superintendencia de Banca, Seguros y AFP, Ley 26702, la empresa fiduciaria no tiene derecho de propiedad sobre los bienes que conforman el patrimonio fideicometido, siendo más bien responsable del mismo"(10).

Por lo expuesto hasta el momento, consideramos que el criterio adoptado por el SAT de Lima es correcto. No obstante,

(8) Ciertamente, el mismo dispositivo legal permite excepciones al plazo de duración, en los casos de fideicomisos de vitalicios, culturales y filantrópicos.

(9) Oficio 001-090-000 de 13 de agosto de 2008 emitido por el SAT- Lima

(10) Oficio 001-090-000 de 13 de agosto de 2008 emitido por el SAT- Lima 


\section{Aspectos problemáticos en los inmuebles sujetos a dominio fiduciario: tratamiento del impuesto de alcabala y las medidas cautelares Problematic areas in the real property subjects to a fiduciary domain: sales tax treatment and the provisionary measures}

atendiendo a que actualmente no existe un dispositivo que reglamente el impuesto de alcabala a nivel nacional,

"admitir que cada municipalidad o SAT tiene la facultad de reglamentar una ley tributaria es contraria a la propuesta de un sistema tributario, toda vez que en el Perú existen 1,833 municipalidades y muchas de ellas administran el impuesto de alcabala. Si cada Gobierno local establece su propio reglamento de impuesto de alcabala, existirían diferentes esquemas legales de tratamiento sobre un mismo impuesto, terminando por generar muchas veces cargas tributarias francamente irracionales, además que se tornaría bastante complejo el tratamiento del referido impuesto a nivel nacional, dificultando el accionar de las grandes empresas que operan en todo el país"(11).

Además, las directivas o lineamientos establecidos por las municipalidades o por sus respectivos Servicios de Administración Tributaria en materia de alcabala son ampliamente cuestionadas en tanto que las municipalidades no son competentes para reglamentar una ley de alcance nacional, como es la Ley de Tributación Municipal. Así pues, en el caso particular de la Directiva emitida por el SAT de Lima,

"si a nuestro entender la Municipalidad Metropolitana de Lima - MML carece de competencia para reglamentar leyes nacionales, entonces también debemos sostener que esta entidad no puede transferir facultades inexistentes a favor del SAT-Lima en torno a la posibilidad de reglamentar a la Ley de Tributación Municipal en la parte que se refiere al impuesto de alcabala"(12).

La misma consideración se extiende para las otras 1,832 municipalidades a nivel nacional.

Como consecuencia de la variedad de criterios que puede ser tomados por las municipalidades en torno a la aplicación del impuesto de alcabala ante la ausencia de un reglamento que desarrolle a la Ley de Tributación Municipal en esta materia, hemos tomado conocimiento que el SAT de Piura ha señalado mediante Resolución de Gerencia General No. 688-2017-SATP, que

"la transferencia en dominio fiduciario importa una sustitución al derecho de propiedad, por cuando el fiduciario quien a través del dominio fiduciario del patrimonio autónomo ejerce aquellas facultades que son estrictamente inherentes a la propiedad, tales como el uso, disposición y reivindicación, tal es así que nuestro ordenamiento civil así como los diversos pronunciamientos en sede judicial respecto al tema, señalan que la acción reivindicatoria es única y exclusiva de quien ostenta el derecho de propiedad, siendo ello así en el caso de la transferencia fiduciaria el fideicomitente pierde todos aquellos poderes sobre el bien fideicometido, poderes que ahora ostenta el fiduciario a través del patrimonio autónomo que es en quien recae la propiedad del bien fideicometido"(13).

Sobre el particular, el SAT de Piura señala que por el solo hecho de que el fiduciario ostenta la facultad de reivindicación, el fideicomitente pierde la propiedad del inmueble, y aunque sea el fiduciario quien ejerza la acción reivindicatoria, el titular propietario del bien fideicometido es el patrimonio autónomo. Increíble.

Nótese que todo propietario puede reivindicar el bien, pero no necesariamente quien ejercita la acción reivindicatoria será propietario. El fideicomiso es un ejemplo de esta última situación. Además, recuérdese a la ahora derogada garantía prendaria. El artículo 1070 del Código Civil (derogado) establecía que el acreedor que había perdido involuntariamente la posesión del bien recibido en prenda, podía

(11) Francisco Ruiz de Castilla, citado por Mario Alva, “¿Qué es lo que debe conocer sobre el impuesto de alcabala?,” I-2.

(12) Francisco Ruiz de Castilla, citado por Mario Alva, “¿Qué es lo que debe conocer sobre el impuesto de alcabala?," I-2.

(13) Resolución emitida a propósito de lo dispuesto por el Tribunal Fiscal en Resolución 12607-7-2015 que declara nula e insubsistente la Resolución Gerencial No. 1605-2013-SATP que resuelve un caso de apelación interpuesta por un administrado (fideicomitente) a quien se le impone el pago de alcabala por habérsele revertido el inmueble aportado al fideicomiso. 
Julio Pozo Sánchez y Carolina Ormeño Flores

ejercer, además de las acciones de defensa de la posesión, la acción reivindicatoria cuando ella correspondiera al constituyente del derecho. Es necesario recordar que en este caso estábamos ante un derecho real de garantía, es decir, un derecho real limitado que se sustenta en un derecho fuente como es el derecho de propiedad, por lo que a pesar que se le otorgó en su momento la facultad de reivindicar al depositario, esta facultad siempre estuvo basada en el derecho exclusivo de propiedad del constituyente del derecho. De ninguna manera se sostuvo que por el hecho de ostentar la facultad de reivindicar, el depositario se convertía en propietario. En efecto, la posibilidad de ejercer la acción reivindicatoria no te hace propietario.

Por otro lado, el SAT de Piura olvida (o no quiere entender) lo señalado por las normas antes citadas que con suma claridad establecen que los inmuebles sujetos a dominio fiduciario están destinados a la consecución de un fin, a un tiempo determinado, y que las facultades otorgadas al fiduciario están limitadas por la finalidad del mismo fideicomiso y por lo que en cada caso particular se establezca en el acto constitutivo del mismo.

En consecuencia, si el inmueble por alguna u otra razón se encuentra en posesión de un tercero, el fiduciario podrá desplegar las medidas judiciales necesarias para recuperar el inmueble y destinarlo a la finalidad establecida por el fideicomitente, entre las cuales se encuentra la acción reivindicatoria, puesto que aunque no sea propietario del inmueble se encuentra legitimado expresamente por la Ley de Bancos y la Ley de Mercado de Valores, dependiendo del tipo de fideicomiso del que se trate.

Asimismo, de acuerdo al artículo 253 de la Ley de Bancos, en caso que la empresa fiduciaria no se oponga a las medidas que afecten al patrimonio fideicometido, pueden hacerlo el fideicomitente o cualquier fideicomisario. A caso, ¿el hecho que el fideicomisario ejerza la acción reivindicatoria significa que se hace propietario del inmueble? Consideramos que los argumentos esgrimidos por el SAT de Piura, carecen de sustento.

\section{La defensa del patrimonio autónomo ante las medidas cautelares}

Como quiera que hemos venido sosteniendo que el fideicomitente no pierde la propiedad de los bienes sujetos a dominio fiduciario, sino que únicamente ve limitadas sus facultades sobre dichos bienes en mérito a un acto voluntario de constitución de un patrimonio fideicometido, podría llegarse a pensar que tales bienes responden por las deudas del fideicomitente, no obstante, ello no es así.

En efecto, la constitución del patrimonio fideicometido conlleva que los bienes que sean transmitidos al fideicomiso salgan de la esfera patrimonial del fideicomitente sin significar que entran a la esfera del fiduciario ni de los fideicomisarios. Por ello, el artículo 253 de la Ley de Bancos señala que el patrimonio fideicometido no responde por las obligaciones del fiduciario o del fideicomitente, ni de sus causahabientes y, tratándose de las obligaciones de los fideicomisarios, tal responsabilidad solo es exigible sobre los frutos o las prestaciones que se encuentran a disposición de ellos, de ser el caso.

De manera muy ilustrativa se menciona que,

\footnotetext{
"los bienes o derechos que forman parte del patrimonio fideicometido no pueden ser objeto de ninguna medida judicial o extrajudicial en relación a las obligaciones y responsabilidades de ninguna de las partes intervinientes salvo en los siguientes casos: cuando las obligaciones o las responsabilidades de las que se trate se refieran a aquellas asumidas por el fiduciario en el ejercicio del dominio fiduciario en el ejercicio del dominio fiduciario y se deriven de los actos que efectúe para el cumplimiento de la finalidad para la cual se ha constituido el fideicomiso, cuando se trate de obligaciones y responsabilidades que hubiesen sido previstas en el documento constitutivo del mismo; y cuando se trate del fideicomisario, respecto a los frutos o las prestaciones que se encuentran a su disposición derivados del fideicomiso" (Corzo de la Colina 2012).
} 


\author{
Aspectos problemáticos en los inmuebles sujetos a dominio fiduciario: tratamiento \\ del impuesto de alcabala y las medidas cautelares \\ Problematic areas in the real property subjects to a fiduciary domain: sales tax \\ treatment and the provisionary measures
}

Sin embargo, advertiremos que en diversos pronunciamientos, el Tribunal Fiscal ha declarado inadmisibles las tercerías de propiedad interpuestas por fiduciarios, respecto de deudas del fideicomitente que la administración tributaria intenta cobrar con los inmuebles sujetos a dominio fiduciario, los cuales forman parte de un patrimonio autónomo distinto al del fideicomitente ¿Ello significa, de algún modo, desconocer lo señalado por el artículo 253 de la Ley de Bancos? En adelante, describiremos al patrimonio autónomo que nace con ocasión a la constitución de un fideicomiso y las medidas idóneas que existen para protegerlo.

\subsection{Titularidad del patrimonio autónomo}

Doctrinariamente existen dos posturas en relación a la titularidad del patrimonio, entendido este como un conjunto de relaciones jurídicas activas y pasivas susceptibles de

La teoría subjetiva señala que el patrimonio necesariamente debe tener un titular. "Se tiene, entonces, como una universalidad jurídica directamente emanada de la personalidad cuyo contenido, más que real es potencial. Como consecuencia de esta teoría toda persona tiene un patrimonio y solamente las personas pueden tenerlo. Nadie tiene más que un patrimonio y el mismo es inseparable e inalienable" (Rodríguez 2005).

Por su parte, la teoría objetiva o económica permite la aparición de patrimonios especiales o autónomos, que coexisten con su patrimonio ordinario, "por lo que constituirían excepción indudable a la afirmación según la cual la persona no puede tener más de un patrimonio, y los denominados autónomos o separados que tienen relevancia jurídica en sí mismos considerados, sin requerir por lo tanto del sustento personal propio de la doctrina clásica" (Rodríguez 2005).

Sobre el particular, respondiendo a la pregunta de que si el dominio fiduciario es un derecho real, se sostiene que "el fiduciario no tiene verdaderos derechos sobre los activos transferidos por el fideicomitente. Aquel no puede considerar que 'sus' derechos y deberes han sido divididos en dos patrimonios: 'su patrimonio personal' y 'su patrimonio fiduciario'. Mientras todos sus acreedores pueden accionar contra "su patrimonio personal", ninguno puede accionar contra 'su patrimonio fiduciario' ¿Qué clase de patrimonio es ese?" (Escobar 2006).

Nótese que, por naturaleza, el fideicomiso implica un patrimonio separado. Así, se señala que

"el fideicomiso es una institución siu generis con características propias. El elemento central del fideicomiso en nuestra opinión la afectación de un patrimonio. El fideicomiso sirve y es útil en tanto se separa y afecta un patrimonio para un fin determinado. Sin este elemento, el fideicomiso no tendría razón de ser ni utilidad alguna. Al separase el patrimonio fideicometido se vuelve prácticamente intocable" (Avendaño 1996).

Independientemente de a quién se le atribuya la titularidad del patrimonio fideicometido ${ }^{(14)}$, es ampliamente reconocido tanto por la doctrina como la normativa que este es autónomo y no responde por las obligaciones del fiduciario o del fideicomitente, ni de sus causahabientes; $y$ que únicamente se encuentran afectos al pago de las obligaciones y responsabilidades que la empresa fiduciaria contraiga en ejercicio del dominio fiduciario por los actos que efectúe para el cumplimiento de la finalidad para la que fue constituido el fideicomiso(15).

\subsection{Intervención excluyente de propiedad en materia tributaria}

En el entendido de que el registro no es constitutivo de la propiedad y que en nuestra realidad el nivel de formalización aún es

(14) Que a nuestro entender no es ni del fideicomitente, ni del fiduciario ni de los fideicomisarios, ni de las personas que recibirán los remanentes luego de terminado el fideicomiso.

(15) Artículo 254 de la Ley de Bancos, el mismo que agrega que "no se encuentran afectos a dicho pago, salvo disposición en contrario, los bienes que integran el patrimonio propio de la empresa fiduciaria, del fideicomitente del fideicomisario y del destinatario del remanente. 


\section{Julio Pozo Sánchez y Carolina Ormeño Flores}

mínimo, es común observar que el titular registral no siempre es el titular real debido a que su derecho no se encuentra inscrito. Es por ello que existen diversos mecanismos destinados a que aquel que no ha inscrito su derecho de propiedad ejercite la defensa de su patrimonio cuando lo vea atacado o vulnerado.

La intervención excluyente de propiedad viene a ser uno de aquellos mecanismos y es utilizada para participar y oponerse en un proceso o procedimiento en el cual el acreedor del titular registral interpone una medida cautelar sobre el bien por una deuda propia o ajena avalada por aquél contraída con posterioridad a la fecha en que dejó de ser propietario del bien.

De acuerdo con el artículo 120 del Código Tributario, cuyo Texto Único Ordenado ha sido aprobado por el Decreto Supremo No. 133-2013-EF, el tercero que sea propietario de bienes embargados, podrá interponer Intervención Excluyente de Propiedad ante el Ejecutor Coactivo en cualquier momento antes que se inicie el remate del bien. Quién conoce la apelación es el Tribunal Fiscal.

Sobre el particular, el referido artículo señala que solo será admitida la intervención excluyente de propiedad si el tercero prueba su derecho con documento privado de fecha cierta, documento público u otro documento que, a juicio de la Administración, acredite fehacientemente la propiedad de los bienes antes de haberse trabado la medida cautelar.

Asimismo, a través de la Resolución del Tribunal Fiscal No. 8184-1-2007(16) se fijó precedente de observancia obligatoria sobre este tema, estableciendo que la tercería o intervención excluyente de propiedad es la vía por la que el tercero ajeno al procedimiento de cobranza coactiva, invoca su derecho de propiedad respecto de un bien embargado por una deuda tributaria correspondiente a otro sujeto (deudor tributario), y tiene como finalidad que se tutele dicho derecho y se impida la ejecución de la medida de embargo sobre el bien que le pertenece.
¿Qué tratamiento les da el Tribunal Fiscal a las intervenciones excluyentes de propiedad aplicadas a los fideicomisos? El caso es el siguiente: el fideicomitente tiene una deuda con SUNAT y el ejecutor coactivo de dicha entidad dispone trabar embargo en forma de inscripción sobre un inmueble, cuyo dominio fiduciario ha sido transmitido previamente al fiduciario, a través de la celebración del contrato de fideicomiso.

Ante esta situación, el fiduciario formula contra la Administración Tributaria una intervención excluyente de propiedad, la misma que es declarada inadmisible en tanto que el fiduciario no ostenta la propiedad del inmueble embargado. El Tribunal Fiscal, que conoce de la apelación, confirma la resolución coactiva basándose en el mismo argumento. En efecto, el fiduciario no se encontró en aptitud de probar que ostentaba derecho de propiedad, de acuerdo a lo dispuesto por el inciso a) del artículo 120 del Código Tributario ${ }^{(17)}$, por la simple razón de que no es propietario. Así pues, en reiterada jurisprudencia, el Tribunal Fiscal ha establecido:

"Que conforme se advierte, los inmuebles materia de embargo constituyen propiedad de (...) quien en su calidad de fideicomitente en el contrato de fideicomiso (...) transfirió el dominio fiduciario de dichos predios al (...) mas no su propiedad, lo cual se encuentra señalado expresamente en el artículo 273 de la Ley 26702, (...)".

Que cabe indicar que en el caso del fideicomiso bancario, si bien los bienes que integran el patrimonio fideicometido dejan de ser objeto de 'pertenencia' del fideicomitente, no integran el patrimonio del fiduciario.

(16) Publicada en el diario El Peruano el 8 de setiembre de 2007.

(17) Solo será admitida si el tercero prueba su derecho con documento privado de fecha cierta, documento público u otro documento que, a juicio de la Administración, acredite fehacientemente la propiedad de los bienes antes de haberse trabado la medida cautelar. 


\section{Aspectos problemáticos en los inmuebles sujetos a dominio fiduciario: tratamiento del impuesto de alcabala y las medidas cautelares Problematic areas in the real property subjects to a fiduciary domain: sales tax treatment and the provisionary measures}

Que tal como se ha señalado precedentemente, la finalidad de la Intervención Excluyente de Propiedad es cautelar el derecho de propiedad de un tercero ajeno al procedimiento de cobranza coactiva y que se impida la ejecución de la medida cautelar trabada sobre un bien que le pertenece, por lo que dado que en el caso de autos los embargos en forma de inscripción trabados mediante las resoluciones coactivas (...) no han recaído sobre bienes que fueron de propiedad de la recurrente, no corresponde amparar la intervención excluyente de propiedad formulada por aquella, por tanto, procede confirmar la resolución apelada”(18).

Nos preguntamos si a través de este tipo de pronunciamientos el Tribunal Fiscal desconoce la autonomía del patrimonio fideicometido. Nosotros creemos que no, pues una cosa es el derecho y otra es la vía a través de la cual se hace efectiva: como lo hace ver el Tribunal Fiscal en la resolución de marras, la vía de la intervención excluyente de propiedad no es la (vía) correcta para proteger, en los escenarios de embargo, el patrimonio fideicometido.

En efecto, por naturaleza, la intervención excluyente de propiedad debe ser interpuesta por el propietario de los bienes trabados con medidas cautelares para ser admitida, y en la medida de que el fiduciario no es propietario de los bienes, se declarará inadmisible toda intervención excluyente planteada por él.

Las normas del Código Procesal Civil que regulan la tercería de propiedad señalan que esta solo puede fundarse en la propiedad de los bienes afectados judicialmente por medida cautelar o para la ejecución, al igual que el artículo 120 del Código Tributario.

No obstante, cuando el Código Procesal Civil regula el aspecto referido a la intervención de terceros en procesos judiciales, señala que puede intervenir en un proceso, además del propietario del bien afectado con la medida cautelar, quien tenga un mejor derecho que el titular de la medida cautelar. En tanto que no hay una norma similar en el Código Tributario ni en el Texto Único Ordenado de la Ley de Ejecución
Coactiva vigente, debemos remitirnos al derecho de petición administrativa regulado en el Texto Único Ordenado de la Ley de Procedimiento Administrativo General, según el cual cualquier administrado con capacidad jurídica tiene derecho a presentarse personalmente o hacerse representar ante la autoridad administrativa, para formular legítima oposición.

En ese sentido, a fin de proteger el bien fideicometido afectado con una medida cautelar trabada como consecuencia de una deuda contraída por el fideicomitente en la Administración Tributaria, el fiduciario debe plantear oposición al amparo de lo establecido por el artículo 116 del Texto Único Ordenado de la Ley de Procedimiento Administrativo General y no la intervención excluyente de propiedad puesto que será declarada inadmisible, de acuerdo al criterio reiterativo (y correcto en tanto el fiduciario no es el propietario de los bienes en fideicomiso) del Tribunal Fiscal.

\section{Conclusiones}

El fideicomiso es una operación útil para el desarrollo de nuestra economía. En muchas ocasiones remplaza a los mecanismos de financiamiento bancario directo, y se presenta como una alternativa que implica una garantía adicional para los acreedores (fideicomisarios), en tanto que se forma un patrimonio autónomo, distinto del deudor (fideicomitente).

En ese sentido, resulta correcto que "el aislamiento de los activos transferidos por el fideicomitente es, qué duda cabe, el efecto que caracteriza el fideicomiso. Así es, una vez constituido el fideicomiso, la

(18) Resolución del Tribunal Fiscal No. 772-4-2015 de fecha 25 de enero de 2015. Así también, encontramos el mismo criterio en las Resoluciones del Tribunal Fiscal No. 2048-10-2015 de fecha 24 de febrero de 2015, No. 2195-4-2015 de fecha 3 de marzo de 2015, así como en la Resolución unipersonal No. 876-10-2014 de fecha 17 de enero de 2014. 


\section{Julio Pozo Sánchez y}

\section{Carolina Ormeño Flores}

ley impide que los acreedores de las partes embarguen los activos fideicometidos" (Escobar 2006). De ahí la importancia y el éxito del fideicomiso.

La confianza que otorga la constitución de un fideicomiso no se debe afectar por la vocación recaudadora de las municipalidades en torno al cobro del impuesto de alcabala aun cuando no se haya configurado el hecho generador que da nacimiento a la obligación tributaria; negando la naturaleza misma del fideicomiso. Y aunque el Tribunal Fiscal no se ha pronunciado aún sobre el tema de fondo en específico, sí hemos podido apreciar que, en reiterada jurisprudencia, ha afirmado que la propiedad de los inmuebles sujetos a dominio fiduciario queda en cabeza del fideicomitente y que el fiduciario únicamente ejercita un dominio fiduciario sobre ellos, que de ninguna manera se puede asemejar al derecho de propiedad.

Siendo así, producto de dicho dominio fiduciario sobre los bienes, el fiduciario tiene la obligación de proteger y ejercitar defensa del patrimonio fideicometido, haciendo uso de los mecanismos y vías efectivas para lograr la eficacia de la protección del patrimonio. En dicha medida, deben ser cautelosos para no caer en el error de intentar encuadrar su defensa en un mecanismo que no resulta idóneo, tal como ha ocurrido en los casos de intervención excluyente de propiedad regulada por el Código Tributario.

\section{Referencias bibliográficas}

Alva, Mario. 2014. ¿Qué es lo que debe conocer sobre el impuesto de alcabala? Actualidad empresarial 306 (primera quincena de julio): I-1 - I-6.

Avendaño, Francisco. 1996. El fideicomiso. Derecho PUCP 50: 343-365.

Corzo de la Colina, Rafael. 2012. El fideicomiso, alcances, alternativas y perspectivas. Themis 62: 1-23.

Escobar, Freddy. 2006. Tradiciones, trasplantes e ineficiencias: el caso del fideicomiso peruano. IUS ET VERITAS 32 (julio): 105-38.

Figueroa, Rosa. 2010. Aspecto tributario del fideicomiso de titulización. Actualidad Empresarial 218 (primera quincena de noviembre): I-18 - I-20.

Lisopraswki, Silvio. 1996. Securitización. En Fideicomiso. Dominio fiduciario. Securitización, $2^{\mathrm{a}}$ ed., Silvio Lisopraswki Y Claudio Kiper, 1-24. Buenos Aires: Depalma.

Rodríguez, Sergio. 2005. El contrato de fideicomiso o fiducia mercantil. En Negocios Fiduciarios: su significación en América Latina, 181-215. Buenos Aires: Lexis Nexis.

Sotomayor, Abdias. 2006. El contrato de fideicomiso: aspectos tributario y civil (en especial en el caso del impuesto general a las ventas. Revista Jurídica del Perú 68 (julio-setiembre): 231-246.

Villanueva, Walker. 2013. El fideicomiso y sus implicancias tributarias. IUS ET VERITAS 47 (diciembre): 264-277. 